\title{
Professionalization and Credentialing
}

\author{
Marvin L. Birnbaum, MD, PhD
}

The trouble with our times is that the future is not what it used to be.

\section{Paul Valéry}

The only use of a knowledge of the past is to equip us for the present. No more deadly barm can be done to young minds than by deprecation of the present. The present contains all there is. It is holy ground; for it is the past, and it is the future.

Alfred North Whitehead

As predicted, the 14th World Congress on Disaster and Emergency Medicine (14WCDEM) in Edinburgh, Scotland was the best World Congress ever. The scope and science of the information exchanged were exceptional and timely, and are testimony to the progress being made in the science of Prehospital, Emergency, and Disaster Medicine. The Congress was well organized, with sessions chaired by experts in their respective areas. It was comprehensive, and it was convened in an outstanding venue that worked well for the Congress. Hats off to Andrew Marsden, in particular, and the members of the Local Organizing Committee for their vision and ability to deliver what the participants wanted and needed, and to the Royal College of Surgeons of Edinburgh for its support and for including the Congress as an integral part of the celebration of its 500th anniversary! All of us who attended, as well as all who will benefit from the summaries of each of the sessions provided by the respective chairs (to be published in the next issue of PDM), should be grateful for the efforts expended on our behalf. Moreover, as one outcome of the meetings conducted during the Congress, the WADEM is implementing changes in its structure and functions to better reflect the current needs of Prehospital, Emergency, and Disaster Medicine. This is reflected in the Edinburgh Statements published in this issue of PDM.

On a less positive note, at least one common, repetitive theme emerged during the Congress presentations: i.e., Why do we not learn from our past experiences? Although previous conferences and much of the published information have identified major problems associated with preparedness and responses to major events, there is little evidence of improvement. Summaries of the problems associated with preparedness and responses to Hurricanes Georges and Mitch published in this journal (PAHO: Evaluation of preparedness and response to Hurricanes Georges and Mitch: Conclusions and recommendations. Prehosp Disast Med 1999;14(2):

21-33.) as well as the Hyogo Declaration from the United Nations' World Conference on Disaster Reduction convened in January 2005 in Kobe, Japan and published in this issue as well as many other published works have produced declarative statements as well as recommendations that, had they been implemented, likely would have improved some of the responses to the reported damage created by the 26 December earthquake in the Indian Ocean. However, it is not surprising that these conferences have not resulted in significant improvements, for no organization has been given the mandate to carry out the recommendations. And, if any agency had been given the mandate, it neither would have had the authority or the resources to implement the actions recommended. So, the perpetuation of problems and mistakes in the responses to such events is not difficult to understand.

Hopefully, as evidenced by the recent Conference organized and implemented by the World Health Organization (WHO) in Phuket, Thailand, changes are forthcoming. The Phuket Conference not only produced many recommendations that are the same old, same old, but also probed deeper into some of the reasons that the same inappropriate responses are being repeated. One of the major problems identified during the Phuket Conference and supported during the presentations during $14 \mathrm{WCDEM}$ was the lack of adequate coordination and control at both national and international levels. This facilitated the uninvited influx of organizations and persons that often were ill prepared and inappropriate to meet the defined needs of the affected populations. And, as cited in previous disasters, many of the needs assessments on which to base such responses were inaccurate. Inappropriate and uncoordinated interventions not only are a waste of valuable resources, they often produce additional burdens on an already severely compromised society. Although, many of the responses were appropriate and some were invited by the governments of the affected population, many inappropriate and poorly coordinated interventions occurred and continue in the face of the largest outpouring of resources for responses to a disaster in world history.

Part of the problems identified by the WHO-Phuket Conference was that there currently is no way to assess the abilities and competencies of the organizations and persons who volunteer to respond to help meet the defined needs of the affected population. Indeed, there is a paucity of trained, professional, and competent personnel to provide either the coordination and control or the actual interventions necessary to meet the needs of the affected population. Though many organizations 
and persons have a self-conceived mandate to assist those stricken by disaster and many are blessed with the resources to do so, the majority of the responding personnel are "short-timers"- - they volunteer for short periods, and then, return to their usual occupations. The experiences are not passed on-with some exceptions, the responders are novices. Currently, there are no explicit standards upon which either to train personnel that respond to such events or to judge their competence. As pointed out in the WHOPhuket documents, that area of the discipline concerned with responses to disasters must be based on specific professional criteria for both the personnel and the organizations who respond to such events. "Disaster tourism" must be eliminated, and those who are responsible for providing the coordination and control of the responses must be trained appropriately and must participate in actual or simulated responses and/or exercises on a regular basis.

However, determination of competence without performance standards is impossible. Moreover, it is not possible to produce competence without educational and training standards. Standards for medical practice in the setting of a disaster in which the health infrastructure is damaged and many of the personnel who provide daily health care to the affected population are not available must be defined, and appropriate training courses that assist individuals and organizations to reach these standards must be developed. In order for this discipline to become a profession, courses must be developed and taught by well-prepared, certified teachers within certified training centers. Although the bulk of the educational and training objectives should be standardized internationally, they must be tempered by local and regional concerns including the culture, climate, and language. Thus, training centers must be placed geographically in regions so that, in addition to teaching to the universal standards, can address the particular needs of the specific region. In addition, objectives for many different levels of responsibility for disaster preparedness and response require definition. The process of defining the minimum standards will be a long and arduous one. Importantly, the Education Committee of the World Association for Disaster and Emergency Medicine (WADEM) has been grappling with the educational issues for more than one year as evidenced by the superb, insightful issues paper published in 2004 (Volume 20(S2): s16-s30) of PDM. An essential element for the development of educational and best-practice standards must be better and more comprehensive, unbiased evaluations of what actually occurs during disasters; these must include the definitions of the effectiveness, efficacy, efficiency, benefits, and costs of all of the interventions delivered.

Numerous complexities accompany a move to improve the competence and professionalization of the discipline of disaster medicine. As with other professional medical disciplines, competence must be determined and be certified by persons who are known to be competent in the specific area for which competence is being evaluated. Currently, there are no organizations at the national or international level that have the mandate, authority, and resources to determine competence. Furthermore, from an operational perspective, there currently exist no mechanisms for a coor- dination and control center to identify or have access to a cache of qualified and certified persons and/or organizations that could be mobilized to meet specific needs. Thus, it is not surprising that the responses in times of disaster continue to be disorganized, often are inadequate, ineffective, inefficient, and may produce negative benefits to the affected populations. Modification of this process will take time, and it is inappropriate to expect sudden and drastic changes. But, we are seeing a beginning.

Several confounding factors must be addressed to allow the all-important process of developing minimum standards to progress. Some organization or organizations must be given the mandate, authority, and resources to proceed. But, who (what organization(s)?) has the mandate, authority, and resources to assign such responsibilities? What organization can take charge?

Access to resources, the assignment of the mandates and authority to accomplish these tasks constitute the greatest obstacles to advancing our practice. Perhaps, some of the donated resources, including a portion of the huge outpouring of economic resources that occurred following the earthquake in the Indian Ocean, should be directed into the development of processes to enhance preparedness and responses to future events. Without access to resources that can facilitate the development of standards for best practices, educational programs and the training centers to promulgate them, and the methods for coordinating national and international responses, as well as the standardized methods to evaluate them, we are destined to continue to repeat the same old problems and errors.

We must set aside our own self-serving biases and move together to enhance competencies through the establishment and institutionalization of minimum medical standards and the education and training of personnel and organizations to these standards. Individual governments will not be able to do this alone, as disasters, by definition, require outside assistance, and hence, involve more than one state.

The time is right, as world attention has been peaked by the tragedy of 26 December. Hopefully, leaders will step forward to assume the responsibilities while the level of awareness is high. The new direction taken by WHO following the Phuket Conference requires submission of progress reports from the invited Conference participants within six months of the Conference. The conclusions reached during the WHO-Phuket Conference and the 14 WCDEM constitute a great start. Now is the time for action, not just words and recommendations-but someone must pick up the ball and run with it so that the future will not continue to be a repetition of the past.

If you cry "Forward", you must be sure to make clear the direction in which to go. Don't you see that if you fail to do that and simply call out the word to a monk and a revolutionary, they will go in precisely opposite directions?

Anton Chekhov

Not to know is bad; not to wish to know is worse.

African proverb 